\title{
$\mathbf{I X}$ \\ Organismen in der Pockenlymphe.
}

Von Dr. Ferdinand Cohn, Professor in Breslau.

Dass in der klaren Lymphe von Kuh- und Menschenpocken organisirte Gebilde vorkommen, liess sich bereits aus den Angaben älterer Beobachter, insbesondere aber aus den Untersuchungen von $\mathrm{Keber}$ (Band 42 dieses Archivs 1868), sowie von Zürn und Hallier (a. a. 0., auch Band 41 und 42 dieses Archivs 1867 und 1868) entnehmen. Keber fand in aller Lymphe eigenthümliche mit Eiterkörperchen nicht zu verwechselnde Körnchenzellen von 7-14 Mikromillimeter $\left(\frac{1}{30}-\frac{1}{50}\right.$ Lin.), welche je $3-20$ kuglige oder länglich ausgezogene, bisquitförmige oder unregelmässig sternförmige Kerne oder Körnchen von 0,7-2,8 Mikromillim. ( $\frac{1}{8} \sigma_{0}$ bis

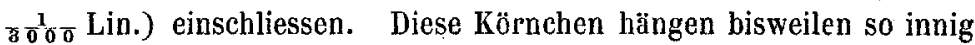
unter einander, dass sie im Stadium der Selbsttheilung zu sein scheinen. Durch Auflösung der zarten Zellhaut werden die Kerne frei und schwimmen in der Lymphe in unzähliger Menge, zu 2, 4-6 durch ein äusserst zartes kaum wabrnehmbares Band verbunden; die Kerne zerfallen wieder stufenweise in kleinere Partikeln und Molecule von fast unmessbarer Kleinheit. Diese Zellenbildungen finden sich, sobald die Pocken überhaupt Lymphe enthalten, vom 4.-5. Tage an; sie haben die Neigung sich zı grösseren oder kleineren Klümpchen und Körnerhaufen zusammenzuballen; in älterer Lymphe (aus Capillarröhrchen) lassen sich mit der Lupe stets Flöckchen und fadenförmige Gerinnsel unterscheiden, welche Conglomerate von Körnchenzellen, freien Körnchen und Moleculen, durch zähe Bindesubstanz verbunden, sind. K eber hält diese Zellbildungen in der Lymphe für die eigentlicben Träger des Pockengifts; unentschieden blieb, ob sie nur durch Exsudate veränderte Kerne des Rete Malpighii (Simon) oder ob sie nicht vielmehr lebendige organische Gebilde seien.

Hallier und Zürn dagegen fanden in der Lymphe von Schaf-, Kuh- und Menschenpocken schwärmenden geschwänzten Micrococcus, 
kegelförmig von Gestalt, lireiselartig bewegk, mitunter in Theilung begriffen, ausserdem die zarten Fäden einer Leptthorix (Mycothrix Itz.), in deren kleinen Keltengliedern man deutlich je einen Micrococcus-Schwärmer erblickte; die Micrococen der Schutzpocken waren zur Ruhe gekommen. Durch sogenannle Cultur glabte Hallier aus dem Micrococcus der Pocken zuerst Sporidien, sodann Cladosporium, Sporidesmium, Tilletia, Monilia, Pleospora herbarum, Oidium Eurotium, Aspergillus, Stemphylium, Ustilago, Torula und noch andere Pilze zu erziehen, welche er sïmmtlich fur Entwickelungsformen oder Morphen der Pocken-Micrococeen erklärt; dureh Einathmung derselben holte er sich einen Bronchialkatarth mit Auswurf desselben bräunlichen Micrococcus, der in den Scbafpocken rorkömmt; dic Schafe selbst verfallen der Krankheit beim Fressen von verschimmeltem Heu.

Es bedarf keines Nachweises, dasa durch die obigen Arbeiten die Frage von den organischen Gebilden in der Poekenlymphe nicht zum Abschluss gebracht worden ist. Seit längerer Zeit mit einer Untersucbung über Bacterien und deren Verbältniss zur Fäulniss und zu Contagien beschäftigt, welche in dew zweiten Hefte meiner "Beiträge zur Biologie der Pflanzen" erscheinen wird, benutzte ich die mir won mehreren hiesigen Aerzten treundlich dargebotene Unterstatzung za einer neuen Untersuchung den Lyrophe ron Vaccine und Variola. Von Herrn Dr. Hirt erhielt ich am 12. November 1871 mehrere Elfenbeinspatel mit eingetrockueter SctutzpockenLymphe aus dem Jahre 1869, welche mit latem destillirtem Wasser 1 Stunde anfgeweicht, in sämmtlichen Präparaten zahllose ausserordentlich kleine, schwach lichtbrechende Kugelchen, frei in der. Flussigkeit schwimmend, oder in zoogloeaartigen Massen vereinigt, erkennen liess. Dasselbe Bild gewabrte aufgeweichte Schutzpocken-Lymphe vom Jahre 1870, welche mir Herr Dr. Ko b ner am 15. Pebruar c. zor Untersuchng uberliess, so dass sich die Angaben von Kaber, welcher berefts Tornchen and feine Kerne in der eingetrockneten Lymphe angibt, bestatigte.

Da jedoch wăhrend der langen Aufbewahrung der getrockneten Lymphe sich möglicherweise fremdartige Gebilde einfinden konnten so untersuchte tch am 23. Februar o völlig klare Vaccine-Lymphe giner Glascapillare, welche Her Dr. Ko öb ner ein par Stunden vorher von einem Kinde abgetmpft hatte, am 1. März die frisehe Lymphe 
aus den Pusteln eines Blatterkranken, welche Herr Dr. Weigert in einer Capillare mir überliess. In beiden Fällen gewann ich das nehmliche Bild unzähliger in fast gleichmässiger Vertheilung frei in der klaren Flüssigkeit schwimmender, seltener paarweise aneinander hängender in Molecularbewegung begriffener, ausserordentlich kleiner kugeliger Körperchen.

Schon der unmittelbare Anblick dieser Gebilde erregte in mir die Ueberzeugung, dass dieselben weder Fetttröpfchen, noch Zellkerne, noch Protoplasmakörnchen, noch körnige Ausscheidungen aus dem Serum der Lymphe, sondern dass sie lebendige einzellige Organismen aus der Gruppe der sogenannten Kugelbacterien seien, dass sie ferner bereits innerbalb der Pustel sich in der Lymphe befinden, nicht erst zufällig von aussen hineingerathen. Dass es mir jedoch gelang, diese Sätze zur Gewissheit zu erheben, verdanke ich der freundlichen Unterstützung des Herrn Geheimrath Lebert, welcher zweimal, arn 10. und 23. März c., Kinder mit schön entwickelten Vaccineblattern auf das Pflanzenphysiologische Institut brachte, die erforderlichen Operationen selbst übernahm und mich dadurch in den Besitz eines Materials versetzte, welches nach der von mir angewendeten Methode eine positive Entscheidung über eine in vieler Beziehung bochwichtige Frage gestattete.

Es kam zunächst darauf an, jede Verunreinigung der Lymphe durch Schimmel und Bacterien von anssen zu verhüten, was aber nur durch Anwendung besonderer Vorsicht, dann aber mit Sicherheit gelingt. Die Pusteln wurden vermittelst einer ungebrauchten Lanzelte geöffnet, die hervorquellenden Lymphtropfen sofort in Glascapillaren eingesangt, dje vorher schwach geglüht waren; wurde die Lanzette selbst zur Uebertragung der Lymphe benutzt, so liess sich eine Verunreinigung durch den Pockenschorf nur schwer verbindern. Aus den Capillarröhrchen wurde die klare Flüssigkeit alsbald vorsichtig mit dem Strohbalm auf ein Objectglas ausgeblasen, welches unmittelbar vorher mit Ammoniak abgewaschen, dann in kochendem destillirtem Wasser abgespült war; das adhärirende Wasser muss durch Abschütteln entfernt werden, da beim Abtrocknen mit dem Leinentuch wieder Verunreinigung zu befürchten ist. Der Lymphtropfen auf dem Objectglas muss möglichst so gross sein, dass er von einem parat gehaltenen, auf gleiche Weise ges 
reinigten Deckglase vollständig bedeckt wird, ohne am Rande oder in der Mitte Luftblasen entstehen zu lassen. Alsdann wurde das Präparat sofort mit dickem Asphaltlack (von Möller in Wedl) an den Rändern sorgfältig verkittet, und theils frisch untersucht, theils behufs weiterer Entwickelung in einen heizbaren Blechkasten gestell, welcher mit Hülfe eines Bunsen'schen Regnlators unter einer constanten Temperatur von ca. $35^{\circ} \mathrm{G}$. erhalten wird.

Dass die in den Capillarröhrchen aufgesangte Vaccine-Lymphe bei geböriger Vorsicht frei von fremden Bacterien und Sehimmelkeimen erhalten werden kann, liess sich durch die von Burdon Sanderson angegebene Methode (Report of researches concerning the intimate pathology of contagion II) erweisen; wurde eine LymphGapillare in einem mit frisch gekochter Pasteur'seher Flussigkeit gefüllten Reagircylinder ausgeblasen, so blieb die Flissigkeit selbst bei einer Temperatur von $30-40^{\circ}$ stets klar und bacterienfrei, wăhrend die geringste Verunreinigung in wenig Tagen Trabung und Fäulniss der Flüssigkeit unter Entwickelung ron Stäbchenbacterien zur Folge hat. Die im verkitteten Präparat eingeschlossene Lymphe kann weder mit Staub, noch mit Luft oder Wasser in Berührung kommen; auch ist in keinem meiner Praparate im Laufe der Zeit Entwichelung von Cylinderbacterien, Schimmeln oder Faulen beobachell worden. Nicht minder ist bei der Untersuchung mit der Immersionslinse das Präparat vor dem Ueberfliessen des Wassertropfens geschutzt, welcher unter anderen Umständen die Reinheit des Objects getäbrdet; auch kann das Deckglass zu jeder Zeit ohne Gefahr vermittelst der Spritzflasche abgespült werden, was wir eine exacte Beobachtung soloh feiner Vexhälnisse von wesentlicher Bedeutung ist. Gauz bespnderen Vortheil aber bietet meine Methode für die Entwickelungsgeschichte der Körperchen in der Lymphe. Wäbrend ein unverschlossenes Präparat in der feuchten Kammer zwar vor dem Austrocknen bewahrt werden kann, aber in Folge der jm dunstgesătigten Raum bei jeder Tempendurinderung niedergeschlagenen Wassertropfen der Verunreinigung durch Bacterien and Fadenpilze auggesetzt bleibt, wie vergleichende Untersuchungen herausgestellt haben, so ist im verschlossened priparate der nachträgliche Zotritt fremder Organismen zur Jymphe selbstxerständlich unmöglich; wohl aber entwickeln sich die in itro primär vorbandenen Körperchen ganz ebenso normal, als ob sie noch in der geschlossenen 
Pustel, oder vielmehr als ob sie in einer Glascapillare eingeschlossen wären, in welcher ja thatsächlich die Lymphe durch lange Zeit unverändert und wirkungskräftig bleibt.

Die durch meine Methode gewonnenen Beobachtungen sind folgende: sie beziehen sich in ganz gleicher Weise auf die Lymphe der Vaccine und Variola, in welcher ich keine mikroskopischen oder entwickelungsgeschichtlichen Verschiedenheiten mit Sicherheit constatiren kann. Das frische Lymphepräparat zeigt sich, wie schon erwähnt, stets reich und̆ fast gleichmässig erfüllt von kugligen Körperchen, die ausserordentlich klein, selbstständiger Bewegung entbehren, aber Molecularbewegung zeigen und in ihrem Lichtbrechungsvermögen von dem Serum nicht sehr verschieden scheinen, daher leicht übersehen werden können. In der That werden dieselben von dem, der sie nicht kennt (etwa wie die Streifensysteme einer Pleurosigma), nur bei günstiger Beleuchtnng und mit der Immersionslinse, dann aber vollkommen scharf und klar aufgefunden werden; bei schlechtem Tageslicht ist die Beleuchtung durch eine Gas- oder Petroleumflamme vorzuziehen; wer die Körperchen einmal gesehen, wird sie auch mit schwächeren Objectiven ( 8 Hartnack, VI Gundlach) wiederfinden. Ihre Grösse lässt sich mit unseren Mikrometern nicht mehr zuverlässig bestimmen; doch liegt sie sicher unter 1 Mikrom. $(0,001 \mathrm{~m}$.$) , ich schätze sie auf die Hälfte bis \frac{3}{4}$ dieser Grösse; allerdings finden sich in der Lymphe auch zahlreiche grössere, stärker lichtbrechende Körperchen, von denen sich schwer entscheiden lässt, in wie weit sie Fettkügelchen oder Entwickelungszustände der kleineren sind. Diese halte ich für Zellen, deren Membran sich als ein heller Ring um den bei gewisser Einstellung schwärzlich erscheinenden Inhalt markirt, wie namentlich bei Theilungszuständen hervortritt. Unmittelbar nach der Herstellung des Präparats sind die Körperchen gewöhnlich einfach, seltener paarweise zusammenhängend, wie eine 8 ; aber schon nach kurzer Zeit vermehrt sich die Zahl der Doppelzellen; bald erkennt man Reihen oder Ketten von 4 an einander hängenden; diese Reihen sind nicht immer gerade, sondern verbogen, oder zickzackartig; offenbar sind die Kettenglieder nicht fest verbunden, sondern verschieben sich leicht. Nach 1 bis 2 Stunden finden wir zahlreiche rosenkranzförmige Ketten meist von 8 Gliedern, an denen das Verschieben noch deutlicher auftritt; die Kügelchen lagern sich dann nicht hinter, 
sondern zum Theil reben einander, oder bilden Sarcine äbniliche Gruppen, die jedoch nicht wie ächte Sarcina von einer Theilung über das Kreuz, sondern von der Verschiebung einer Längsreihe ibren Ursprung nehmen. Offenbar sind die Körperchen der Lymphe in ausserordentlich rascher und ununterbrochener Vermehrang begriffen, die ursprünglich nur durch Quertheilung mit parallelen Scheide-Wanden (resp. durch Abschnürung) vor sich gebt, so dass die Tochterzellen in einfachen Kettenreihen liegen, wie die Glieder

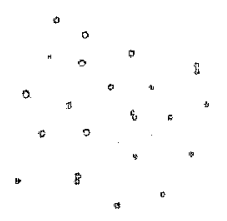

Frische Pockentymphe iा

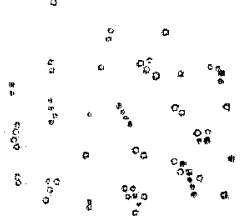

Lymphe nach 2 Stunden $\pi \frac{1}{0} 0$.

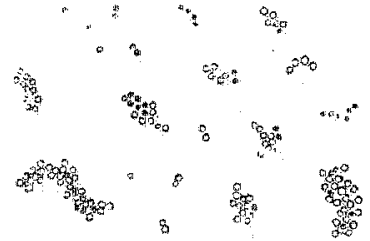

Lympe nach 8 Stunden

eitus Confervenfaden oder die Sporenketten eines Penicillium. In Folge des geringen Zusammenhanges, welchen die Körperchen einer Reibe besitzen, entstehen jedoch bei stets fortdauernder Vermehrung alle möglichen Gruppirungen, an denen anfangs noch die ursprüngliche Lagerung erkennbar ist; aber schon nach etwa 6 Stunden werden dieselben zu unregelmässigen Colonien oder Zellhäufchen, die aus zahlreichen $(16-32$ und mehr) Körperchen bestehen, doch finden sich um diese Zeit in der Lymphe inmer roch vereinzelte Glieder oder zu 2, 4-8 zusammenhäugende Beiben, welche die Genesis der Häufchen verfolgen lassen. Die Zellvermehrung dauert durch mehrere Tage fort; die Häufchen werden daher immer grösser und erreichen 10 Mikrom. und mehr. Uebt man einen leisen Druck auf das Deckglas, so brecher die einzelnen Körperehen eines Häufchens leicht aus einander und jsoliren sich. Es ist wohl nicht zu bezweifeln, dass der Zellvermehrungsprozess unter dem Deckgläschen in der nehmlichen Weise ror sich geht, wie er auch in der Pockenpustel stattgefunden baben würde; wenn man in der frischen Lymphe die Körperchen meist nur isolirt sieht, so seheint mir die Ursache in den Strömungen der Flussigkeit im lebendigen Menschen zu liegen, welche die Theilungszellen sofort aus einander meisst, wäbrend im atbgeschlossenen Raum des Präparats sämmliche aus einer Zelle 
hervorgegangenen Generationen im Zusammenhang bleiben. Bekanntlich erhalten wir auch von der Bierhefe, wie schon Mitscherlich zeigte, nur dann zusammenhängende Sprossbäumchen, wenn dieselbe in der feuchten Kammer unter dem Deckglas cultivirt wird, während in der gährenden Flüssigkeit die Hefezellen meist nur paarweise aneinanderhängen, weil die Sprossungen durch die Strömung alsbald losgerissen werden.

In einer Glascapillare scheint die Vermehrung in den Zellcolonien noch lange Zeit fortzudauern, daher die Häufchen bedeutendere Grösse annehmen und als Gerinnsel oder Flöckchen erscheinen. Durch Entwickelung schleimiger Zwischensubstanz aus den aufgequollenen Zellhäuten treten die Körperchen in irnigeren Zusammenhang (Zoogloea-Bildung); die Grösse der einżelnen Zellen nimmt zu, ihr Inhalt wird stärker lichtbrechend, ölartig (Bildung von Datnerzellen?); indem die Hüufchen durch Ausscheidung fremder Substanzen aus der Lymphe incrustiren, lässt sich ihr Ursprung aus den kleineren Colonien und Ketten nicht jmmer deutlich erkennen; dass gleichzeitig zahlreiche raphidenartige Krystallnadeln in der Lymphe auftreten, ist bekannt.

Wir baben nun zu untersuchen, wie sich unsere Beobachtungen $z u$ denen von $K$ eber, Hallier und $Z$ ü $r n$ verhalten. Dass unsere Körperchen mit denen identisch sind, welche Keber in seiner sehr sorgfältigen Arbeit als unmessbare Molecule, zum Theil auch mit denen, die er als Körnchen bezeichnet, ist wohl nicht zu bezweifeln; dagegen ist mir nicht klar, was derselbe unter „Körnchenzellen und dem aus diesen heraustretenden Kernen" verstandeu hat. In der Variolalymphe, wie in unreiner Vaccine, fanden sich zahlreiche Eiterkörperchen, in denen stark lichtbrechende Körnchen (Fett?) sich entwickeln und durch Zersetzung der Eiterkörperchen frei geworden, auch in der Lymphe in grösster Zahl zu finden sind; sie unterscheiden sich jedoch von den eigentlichen Pockenkörperchen durch ihre meist bedeutendere Grösse, wie durch ihre stärkere Lichtbrechung; in kJarer Lymphe sind solche Körnchen ebenso wenig, wie Eiterkörperchen zu finden. Keber hat in treffender Weise auch die Beschreibung der Klümpchen und Körnchenhaufen der älteren Lymphe gegeben; nur ist ihre Entstebung nicht aus dem Zusammenballen isolirter Körver, sondern aus der Colonienbildung durch wiederholte Theilung abzuleiten. 
Auch Hallier hat, soweit aus seinen Darstellungen sich sichere Schlüsse ziehen lassen, die Körperchen in der Lymphe gesehen, und sie als Micrococcus bezeichnet. Allerdings finde ich dieselben weder geschwänzt oder kegelförmig, noch schwärmend, sondern stets kuglig und unbewegt, Hallier selbst erwähnt in der Vaccine zur Ruhe gekommenen Micrococcus. Unter Leptothrix oder Mycothrix scheint Hallier die Kettenbildung durch Quertheilung (Abschnutrung) zu verstehen; was dagegen die angebliche Entwickelung des Micrococeus aus und zu allen möglichen Fadenpilzen betrifft, so begnüge ich mich darauf hinzuweisen, dass ich bis jetzt weder bei den Körperchen der Pockenlymphe, noch bei analogen Gebilden (Kugelund Cylinderbacterien) eineu entwickelungsgeschichtlichen Zusammenhang mit Hefe oder irgend einem anderen pilze habe aufinden können.

Wir müssen daher für jetzt die Körperchen der Pockenlymphe als lebende und selbständige Organismen betrachten, zu der Klasse der Schizomyceten gehörig, welche als die kleinsten und einfachsten aller Wesen, ohne Mycelbildung, sich nur durch Zelltheilung, vielleicht auch durch Bildung von Dauerzellen, vermehren. Von den ihnen anscheinend am nächsten stehenden Cqlinder- oder Stäbchenbacterien unterscheiden sich die Pockenlymphkörperchen und die ihnen verwandten Formen aw leichtesten durch die Form ihrer Zellen, welche kuglig oder oval, nicht cylindrisch ist; auch scheinen sie der charakteristischen Bewegung der Bacterien zu entbehren. Die Rosenkranzform ihrer Zellreihen scheint auf eine eigenthumliche Modification der Theilung (Abschnürung) hinzwweisen; doch lässt sich ihrer Kleinheit wegen der Vorgang nich genau verfolgen. Ich habe in fruheren Mitheilungen derartige Korperchen als Kugelbacterien bezeichnet, ich würde ibnen den Hallier' schen Namen Micrococcus beigelegt haben, wenn nicbt eben die Natur dieses Micrococcus so problematisch wäre, und insbesondere die angebliche Entstehung des Micrococcus als Schwärmsporen qus Hefe oder Fadenpilzen und dessen Keimung zu Mycelfaden atc. auf unsere formen keine Anwendung fänden. Es scheint mir daher nothwendig, die kobrperchen der Vaccine und Variola, wie die thnen nächst verwandten Gebilde, mit einem besonderen Namen und mit folgendem Charakter zu belegen: 
Microsphaera (Kugelbacterie).

Familie der Schizomyceten, Gruppe der Bacteriaceae.

"Zellen farblos, sebr klein, kuglig oder sphäroidisch, in der Regel unbewegt, durch Theilung oder Abschnürung zu 2, 4-8 oder mehrgliedrigen rosenkranzförmigen Ketten vermehrt, durch Versehiebung zu unregelmåssigen Gruppirungen, in Folge fortgeschrittener Vermehrung zu zahlreichen Zellhäufchen oder Colonien entwickelt, oder durch schleimige Intercellularsubstanz zu zoogloeaartigen Massen verbunden, vielleicht Dauerzellen bildend."

Wenn wir schliesslich die Frage erörtern sollen, ob die Microsphären der Vaccine und Variola die Träger des Contagium sind, so lässt sich nach meiner Ansicht aus den bisherigen Untersuchungen eine positive Entscheidung noch nicht geben; doch spricht ein Ueberblick über die ermittelten Thatsachen mit grosser Wahrscheinlichkeit für die Bejahung der Frage.

Es ist festgestellt, dass die Microsphären in aller Pockenlymphe und in grösster Zahl auftreten, dass sie sich ansserordentlich rasch vermehren; dass dieselben weder zufällige, noch secundäre Bildungen sind, ergibt sich aus der Entdeckung von C. Weigert, welche unterm 30. Angust $1871 \mathrm{im}$ medicin. Centralblatt (No.39) in einer vorläufigen Mittheilung publicirt wurde; derselbe fand bei Pockenleichen die Kanälchen der Pockenhaut sehr oft mit äusserst kleinen dicht an einander gelagerten kugligen Körperchen vollgestopft, welche ich nach Vergleichung der mir freundlichst vorgelegten Präparate nicht anstehe, hier identisch mit den Microsphären der Lymphe zu erklären; diese Körperchen scheinen hiernach zugleich mit dem Serum aus jenen Kanälchen ausgeschieden $z u$ werden. Nun hat schon Keber gezeigt, dass in der Lymphe gerade diejenigen Theile, in welchen die Gerinnsel der Körperchen am reichlichsten sich finden, auch die grösste Wirksamkeit haben; und aus seinen sinnreichen Diffusions-Versuchen hat Chauvea u mit grosser Wahrscheinlichkeit den Schluss gezogen, dass der Ansteckungsstoff der Schafpocken nicht in der Lympheflüssigkeit, sondern in ausserordentlich kleinen festen Körperchen enthalten sein müsse. Die Microsphären der Pocken stehen in näcbster Verwandtschaft mit anderen Kugelbacterien, von denen meine eigenen Versuche nachgewiesen baben, dass dieselben stets eine Spaltung der Molecule in den Verbindungen erregen, in denen sie sich entwickeln, dass dieselben als Fermente 
wirken und eigenthümliche Producte crzeugen. Kugelbacterien entwickeln sich im Harn, in der Milch, im Eiweiss, auf gekochten Kartoffeln, Eiern und anderen Speisen, auch in chemischen Lösungen und erzeugen durch Spaltung derselben in der Regel alkalische, oft sehr charakteristisch - (gelb, orange, roth, blau oder gräa) gefärbte Verbindungen, daber sie sich schon dem blossen Auge gewöbnlich als farbige Flizsigkeiten oder Gallerttropfen erkennbar machen. Endlich sind, soviel ich weiss, in allen pathologischen Prozessen bis jetzt nur Kugelbacterien aufgefunden worden; namentlich im Blute kran-. ker Raupen und anderer Insecten trat sehr häufig eine Entwickelung von Microsphären ein, welche alkalische Reaction des Bluts, Bildung von Krystallnadein, und früher oder später den Tod des Thieres zur Folge hat. Die eigentliche Fäulniss dagegen scheint nie voa Kugelbacterien, sondern ausschliesslich von Cylizder- oder Stubchenbacterien erregt; wenn wie dies in der Regel der Fall ist, sich gleichzeitig beide Formen in einer Flüssigkeit entwickeln, so werden die Spaltungsproducte der Mierosphären durch die überwiegende Vermehrung der Cylinderbacterien bald unterdruckt und durch die von letzteren eingeleitete Fäuniss wieder zerstört. Es ist daher gewiss nicht unwahrscheinlich, dass auch die Microsphären der Pockenlymphe als Fermente auftreten, dass sie ein Spaltungsproducli des Lymphserum emengen, welches auf einen thierischen organismus ubertragen and in seine: Blutcirculation aufgenommen, eine Störung des normalen Lebens und den Eintrit pathologiseher Prozesse zur Folge hat. Nach dieser Anschauung sind die Microspbären allerdings die Vermittler des Contagiums, aber sie sind nichl sowohl die Träger, als die Erzeuger des Pocliengiftes. leh bin noch damit bescbäftigt, die Tragkraft dieser Hypothese mit Hulfe des Experiments zu erproben, und behalte mir weitere Mitheilungen itber diesen Punkt, sowie die Erörterung der Frage vor, in wieweit die Annahme verschiedener Species für die bei den pocken und in anderen Fillen auftretendea Mierosphären und verwandten Organismen gereehtfertigt ist.

Breslă, den 27. Mär 1872. 